\title{
PAPER
}

\section{Axial rotation in Parkinson's disease}

\author{
M Vaugoyeau, F Viallet, R Aurenty, C Assaiante, S Mesure, J Massion
}

See end of article for authors' affiliations

....................

Correspondence to: Marianne Vaugoyeau, CNRS Groupe DPA, UMR 6196, CNRS, 31 Chemin J Aiguier, 13402 Marseille Cedex 20, France; vaugoyau@dpm.cnrs-mrs.

Received 26 July 2004 Revised version received 17 March 2006

Accepted 20 March 2006

Published Online First 30 March 2006

\begin{abstract}
Aims: To investigate the ability of patients with Parkinson's disease to perform a rotation around the longitudinal axis of the body. Three questions were raised. Is body rotation impaired in Parkinson's disease? Is there a level of the kinematic chain from the head to the foot at which the impairment is more severe? Is the deficit related to the general slowness of movement in Parkinson's disease?

Methods: Kinematic data were recorded. The temporal organisation of body rotation during gait initiation was analysed in 10 patients with Parkinson's disease, who were all at an advanced stage of the disease and had all experienced falls and freezing during their daily life, and in five controls. The latency of the onset of the rotation of each segment was measured by taking the onset of the postural phase of step initiation as reference value. Locomotor variables were also analysed.

Results: Body rotation was found to be impaired in patients with Parkinson's disease, as the delay in the onset of the rotation of each segment is greater than that in controls. Moreover, a specific uncoupling in the onset of shoulder and pelvis segment rotation was seen in patients. This impairment of rotation is not related only to the general slowness of movements.

Conclusion: Patients with Parkinson's disease were found to have an impairment of posturo-kinetic coordination and impaired capacity to exert appropriate ground reaction forces to orient the pelvis in space.
\end{abstract}

M any aspects of motor performance are impaired in people with Parkinson's disease. One aspect that has rarely been investigated is the ability to perform whole-body rotations around the longitudinal axis of the body. Turning in bed is markedly impaired in these people. ${ }^{2}$ A reduction in longitudinal spinal rotation in seated subjects during a reaching task has also been observed in Parkinson's disease. ${ }^{3}$ Steiger $e t$ al ${ }^{4}$ have indicated difficulty in coordinating the orientation of the superimposed axial segments along the body's spinal axis in patients with Parkinson's disease. The patients also show a marked deficit in performing a wholebody rotation on the spot while standing. Moreover, the "impairment of turning in bed" is usually assessed as an item of daily life activities in Unified Parkinson's Disease Rating Scale (UPDRS). ${ }^{5}$ This axial disorder has also been described during walking (directional changes, half turns) and is associated with the "freezing" phenomenon. When asked to turn on the spot, patients perform the action very slowly and execute the rotation by taking little steps (Vaugoyeau et al, unpublished). It is not clear, however, whether the marked impairment of axial rotation is related to a specific deficit in the coordination of the superimposed segments or to a deficit caused by the change in body orientation in space. We can emphasise the role of specific constraints related to postural organisation, which requires coordination between sensory inputs and multijoint outputs. Schieppati et $a l^{6}$ have shown that the stability limits are reduced in Parkinson's disease, which is in agreement with the postural instability described in the late stages of the disease. The static and dynamic postural deficits in patients with Parkinson's disease have been related to an impairment of postural reactions, mainly in the extensor muscles. ${ }^{78}$ Another sensory deficit concerns the body's graviceptors, more specifically those that monitor the force exerted by the extensor muscles. ${ }^{910}$ As a result, patients rely more on vision and on flexor muscles to regulate balance ${ }^{11}$ or locomotion. ${ }^{12}$ The deficit in producing dynamic ground reaction forces is also characteristic in Parkinson's disease, ${ }^{13}$ especially during initiation of gait and locomotion. ${ }^{14-17}$ These deficits, however, are related to posture and gait in general and do not explain why rotation along the longitudinal axis is more impaired in whole-body rotation than during the initiation of gait.

This study explores the possibility that a deficit in axial body rotation while standing does exist in patients with Parkinson's disease, when performing a task that fulfils two requirements: the task has to be similar to a natural task that is easy to perform and has to involve the whole-body axis from the head to the feet, to see whether the impairment of body axis rotation may more specifically involve a given segmental level. The selected task fulfilling the two criteria was a single step at an angle of $45^{\circ}$, which involved a wholebody reorientation in the same direction (fig 1). Three questions were raised. Is the body rotation that takes place in this task impaired? Is there a level of the kinematical chain at which the impairment is more severe? Is the deficit related to the velocity of the movement?

\section{METHODS}

\section{Participants}

Ten patients with Parkinson's disease aged 55-70 years (mean 62.2 (SD 5.5) years) and five age-matched controls aged 56-69 years (mean 61.8 (SD 5.4) years) participated in this study after giving their informed consent. The local ethics committee (Cancer Control using Population-based Registries and Biobanks) approved the project.

Table 1 shows the clinical status of the patients. The patient group was functionally homogeneous as assessed by the UPDRS (normality test: $\mathrm{K}=0.16, \mathrm{p}>0.2$ ). All patients were taking their usual antiparkinsonian drugs and were tested during the pharmacologically "on" status. All patients were at an advanced stage of the disease and they had all experienced falls while walking, as well as the freezing phenomenon. The controls did not have any neurological or other diseases, which may affect their postural stability or ability to perform the experimental tasks.

Abbreviation: UPDRS, Unified Parkinson's Disease Rating Scale 
Table 1 Characteristics of the disease in the 10 patients with Parkinson's disease

\begin{tabular}{|c|c|c|c|c|c|c|c|c|c|c|}
\hline \multirow[b]{2}{*}{ Characteristic } & \multicolumn{10}{|l|}{ Patient } \\
\hline & 1 & 2 & 3 & 4 & 5 & 6 & 7 & 8 & 9 & 10 \\
\hline $\begin{array}{l}\text { Duration of disease } \\
\text { (years) }\end{array}$ & 18 & 10 & 10 & 29 & 13 & 19 & 6 & 12 & 8 & 12 \\
\hline Hoehn-Yahr stage & III & III & III & IV & III & III & III & IV & IIII & IV \\
\hline $\begin{array}{l}\text { UPDRS part III } \\
\text { in the on state }\end{array}$ & 30 & 19 & 28 & 33 & 22 & 24 & 31 & 35 & 25 & 31 \\
\hline $\begin{array}{l}\text { UPDRS part III } \\
\text { in the off state }\end{array}$ & 45 & 57 & 40 & 65 & 38 & NA & 40 & 48 & 44 & 44 \\
\hline $\begin{array}{l}\text { Levodopa (mg/day); } \\
\text { duration (years) }\end{array}$ & $1750 ; 14$ & $1000 ; 8$ & $1000 ; 8$ & $2200 ; 25$ & $850 ; 12$ & $800 ; 18$ & $400 ; 5$ & $1350 ; 10$ & $1200 ; 8$ & $600 ; 10$ \\
\hline $\begin{array}{l}\text { Other drugs, } \\
\mathrm{mg} / \text { day }\end{array}$ & $\begin{array}{l}\text { Bromocriptin } \\
15\end{array}$ & $\begin{array}{l}\text { Pergolide 6; } \\
\text { Amantadine } \\
300\end{array}$ & $\begin{array}{l}\text { Bromocriptin } \\
40 ; \\
\text { Amantadine } \\
300\end{array}$ & $\begin{array}{l}\text { Pergolide 3; } \\
\text { Amantadine } \\
300\end{array}$ & $\begin{array}{l}\text { Piribedil 100; } \\
\text { Segiline } 10\end{array}$ & $\begin{array}{l}\text { Bromocriptin } \\
50 \text {; Segiline } 10\end{array}$ & None & & & $\begin{array}{l}\text { Trihexipphenidyle } \\
4\end{array}$ \\
\hline $\begin{array}{l}\text { Lisuride } 0.8 ; \\
\text { Segiline } 10\end{array}$ & \multicolumn{10}{|c|}{$\begin{array}{l}\text { Bromocriptin } 15 \\
\text { Trihexipphenidyle } 10 \\
\text { Tolcapone } 600\end{array}$} \\
\hline
\end{tabular}

\section{Experimental procedure}

The task was analysed by using a multiparametric method combining kinetic and kinematic variables. It consisted of taking a single diagonal step of an angle of $45^{\circ}$ and ended when the other leg (trailing leg) was placed parallel to the first moving leg. Participants had to take the diagonal step accompanied by body reorientation in the direction of the step, and then end the task with their body oriented in the $45^{\circ}$ angle direction. A triggering signal was given by a sound emitted by a loudspeaker situated in the required step direction $\left(45^{\circ}\right)$. No instruction was given about the speed of execution. Ten trials were recorded for each participant. Before each trial, they stood erect, unsupported and barefoot on a force platform (AMTI; Advanced Mechanical Technology, Watertown, Massachussetts, USA). Participants were instructed to adopt the same initial posture with the head upright and looking straight ahead, and to take the step with the same leg-the one that they used to initiate walking. All participants but one initiated the step with the right leg.

\section{Experimental recordings}

The recording duration was $3 \mathrm{~s}$ for each trial and horizontal and vertical components of the ground reaction forces were recorded by using a force platform with a sampling frequency of $500 \mathrm{~Hz}$ (AMTI). Kinematic analyses were carried out with the ELITE television image-processing system. ${ }^{18}$ For this purpose, 14 reflective markers $(1 \mathrm{~cm}$ in diameter) were placed symmetrically in pairs: at the level of the external angle of the eye orbit, the shoulder acromion, anterosuperior iliac spine, great trochanter, knee external malleolus and fifth metatarsus. Recordings were taken with four infrared cameras and kinematic profiles were monitored at a sampling rate of $100 \mathrm{~Hz}$.

\section{Step variables}

For all variables, we analysed the first step-that is, the one performed during body rotation.

On the basis of kinetic and kinematic variables, two successive phases were defined for controls and patients with Parkinson's disease: the postural phase and the movement phase. ${ }^{16}$ The postural phase started at $\mathrm{Tl}$, with the first variation of the horizontal force in the sagittal plane (Fy), and ended at T2, which corresponded to the onset of deflection of the velocity curve of the malleolus marker of the leading leg (fig 2). The movement phase corresponded to step execution, beginning at $\mathrm{T} 2$ and ending at $\mathrm{T} 3$, when the first moving leg struck the ground. T3 corresponded to the zero crossing of the velocity curve of the moving malleolus.
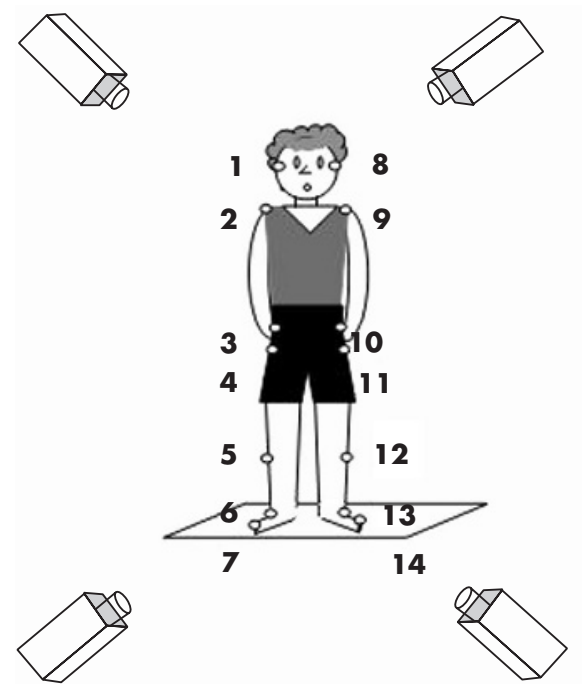

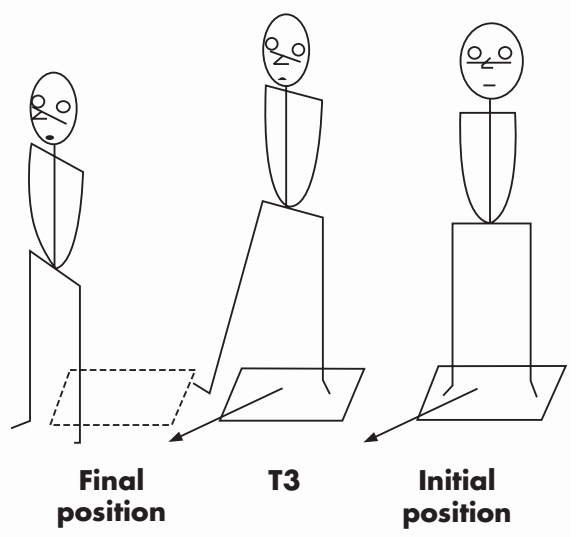

position

position

Figure 1 Experimental set-up and task. On the left: representation of the subject in the initial position with the location of the 14 markers; on the right: experimental task; single diagonal step with reorientation. 
Control

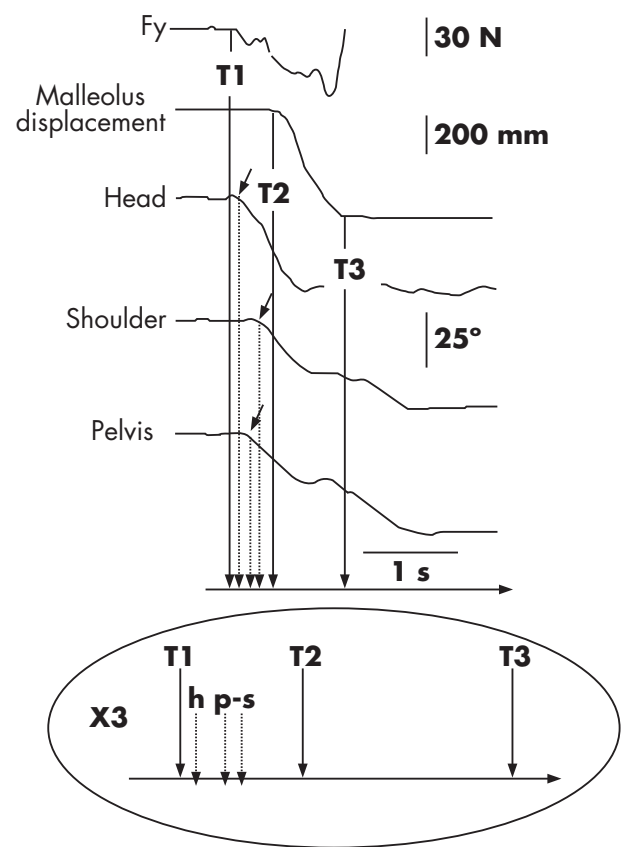

Patient with Parkinson's disease

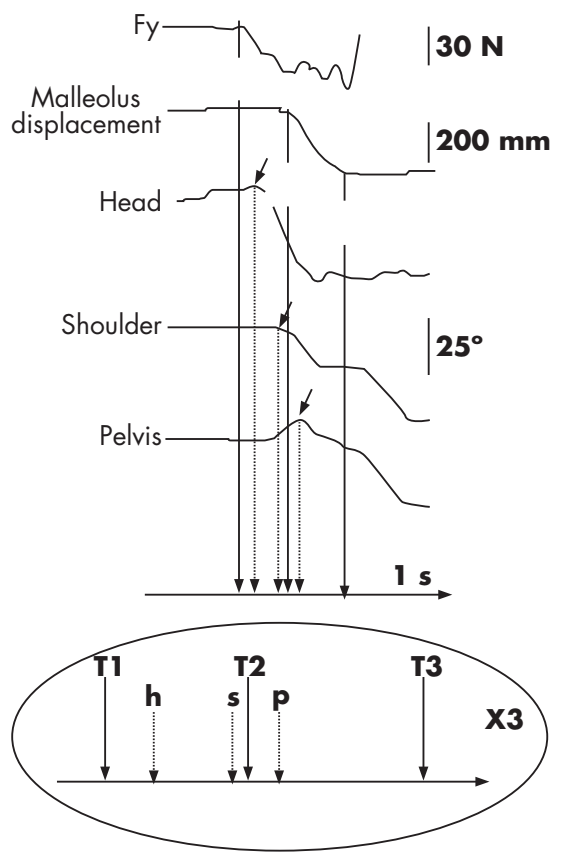

Figure 2 Single trial recording of body rotation: left, control; right, a patient with Parkinson's disease. Top: kinetic (Fy: horizontal forces in the sagittal plane), kinematic (malleolus displacement) and angular data. The horizontal rotation around the vertical axis (yaw), angular variation of the head, the shoulders and the pelvis are shown. The small arrows indicate the onset of rotation of each segment. Bottom: representation of the temporal organisation of the rotation. Controls begin shoulder and pelvis rotation simultaneously with their axial body rotation, whereas patients with Parkinson's disease start shoulder ( $s$ ) rotation before pelvis (p) rotation. Trunk rotation is uncoupled. T1, start of the postural phase (first variation in the horizontal forces in the sagittal plane); T2, end of the postural phase corresponding to the beginning of the movement phase (first variation in the velocity of the malleolus marker); T3, end of the movement phase (first contact of the foot with the floor).

Step length was measured in the step direction from the trajectory of the malleolus marker of the first moving leg. To verify this $\left(45^{\circ}\right)$, the angular direction of the step was measured, from the curve of the malleolus marker displacement of the moving leg, as the angle change between the initial anteroposterior direction and the final direction defined by the path of the step.

\section{Body rotation}

Whole-body reorientation in the step direction was investigated. The horizontal rotation around the vertical axis (yaw) of three segments was considered-those of the head, the shoulder and the pelvis-then corresponding to the lines between markers 1 and 8 (head), 2 and 9 (shoulders) and 3 and 10 (pelvis).

\section{Angular variables}

Two angles for each segment were defined as follows:

1. the angle between the initial position and the position at T3 (that corresponds to the end of the first diagonal step; $\alpha \mathrm{l}$ for the head, $\beta \mathrm{l}$ for the shoulders and $\gamma \mathrm{l}$ for the pelvis);

2. the angle between the initial position and the end of the body rotation ( $\alpha 2$ for the head, $\beta 2$ for the shoulders and $\gamma 2$ for the pelvis).

Temporal variables

For each segment, the onset time of the rotation was measured, which corresponded to the onset of angular variation from the initial position in the horizontal plane. The latencies of the onset of rotation of each segment were calculated by taking the first variation in the horizontal forces in the sagittal plane ( $\mathrm{Tl}$ ) initiating the postural phase as a reference. These time intervals were called head (Th), shoulder (Ts) and pelvis (Tp) onset latencies.

\section{Statistical analysis}

Data were analysed with the Statistica program Statsoft. Descriptive statistics are reported as mean (SD). The mean of each group corresponds to the average of the mean values of the 10 trials performed for each participant.

Differences between the groups were tested with the Mann-Whitney $U$ test. The comparison between latency of segments in each group was made with the Wilcoxon's signed rank test (for within-subjects comparisons).

One-sample analysis (t test) was used to compare the step trajectory to the $45^{\circ}$ required. To determine whether the segmental rotation was simultaneous with the onset of the postural phase, we compared the onset of the latencies of each segmental rotation to 0 , by using one-sample analysis $(\mathrm{t}$ test). A correlation analysis between the body's kinematic variables and step velocity was carried out in both groups. A coefficient of correlation not significantly different from zero would show that the impairment of rotation would not be related only to the general slowness of movements. We checked that all the data analysed with a t test were normally distributed (Kolmogorov-Smirnoff test).

Differences with $\mathrm{p}<0.05$ were considered to be significant.

\section{RESULTS}

To assess how accurately the instructions of step direction in both control and patient groups were followed, original and final orientations of the head were compared with $45^{\circ}$ (figs 3 , 4). Step direction was successfully carried out. The deviation of the direction of step trajectory from the required $45^{\circ}$ was 

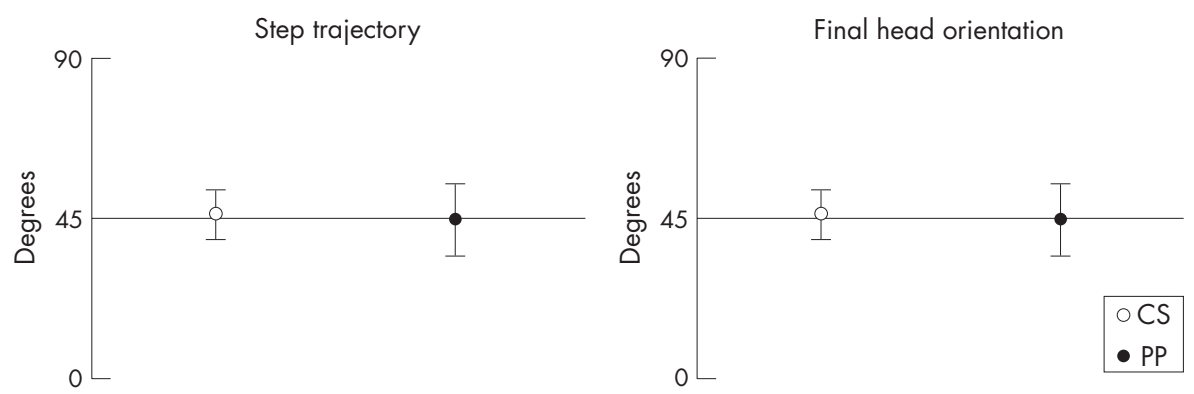

Figure 3 Mean (SD) step trajectory (left) and final head orientation (right) of controls (CS, white) and patients with Parkinson's disease (PP, black).

not significantly different for controls $(\mathrm{t}=1.8 ; \mathrm{p}>0.05)$ and patients with Parkinson's disease $(t=0.2 ; \mathrm{p}>0.05)$, and the final orientation of the head was not significantly different from $45^{\circ}$ for controls $(\mathrm{t}=-0.29 ; \mathrm{p}>0.05)$ and patients with Parkinson's disease $(\mathrm{t}=0.92 ; \mathrm{p}>0.05)$.

\section{Comparison between groups}

Analysis of the step variables

Phase duration, step length, step velocity

The duration of the postural phase was significantly longer in the patients than in the healthy controls (330.30 (78) $v$ 239.30 (70.38) s; $U=3.62 ; \mathrm{p}<0.001)$. The duration of the movement phase was significantly shorter in patients than in

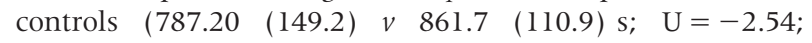
$\mathrm{p}<0.05$ ).

The step length in the patients with Parkinson's disease group was significantly decreased compared with that in the control group (302.40 (77) v 422.30 (8.32) $\mathrm{mm}$; $\mathrm{U}=-6.67$; $\mathrm{p}<0.001)$. Step velocity was reduced in patients compared with that in controls (389.5 (94.94) $v 495$ (10.9) mm/s; $\mathrm{U}=-5.12 ; \mathrm{p}<0.001)$.

\section{Analysis of body rotation}

Figure 5 shows the respective angular rotation amplitudes of the head, the shoulders and the pelvis at T3 $(\alpha 1, \beta 1, \gamma 1)$ and at the end of the task $(\alpha 2, \beta 2, \gamma 2)$. Figure 6 shows the latencies from $\mathrm{Tl}$ to the onset of rotation for the three segments studied (head, shoulders and pelvis).

\section{Amplitude of rotation of segments}

When compared with healthy controls, patients with Parkinson's disease presented with a significant decrease in the amplitude of pelvis rotation at $\mathrm{T} 3\left(35^{\circ}\left(11.2^{\circ}\right)\right.$ and $38.3^{\circ}$ $\left(10.7^{\circ}\right) ; U=5.15 ; p<0.05$; fig 5$)$. Rotations of the head and shoulder, however, were similar in both groups at $\mathrm{T} 3$ and at the end of the task.

\section{Onset of rotation of segments}

For the three segments studied (head, shoulders and pelvis), the latencies of the onset of the rotation from Tl (Th, Ts and $\mathrm{Tp}$, respectively) were significantly longer in patients with Parkinson's disease than in controls: head, $\mathrm{U}=-3.5 \mathrm{l}$; $\mathrm{p}<0.001$; shoulders, $U=-2.34 ; \mathrm{p}<0.05$; and pelvis, $\mathrm{U}=-3.65 ; \mathrm{p}<0.001$. This indicates a global delay in the onset of body rotation in patients with Parkinson's disease (fig 6).

\section{Comparison within groups}

Temporal organisation of body rotation

The comparison between groups showed a significant delay in the onset of rotation of each segment in patients with Parkinson's disease (fig 6). To determine possible changes in the organisation of rotation, the latencies of head, shoulders and pelvis were statistically analysed for both groups.

In controls, the latency of head rotation (Th) was not significantly different from 0 , indicating that the onset of the postural phase ( $\mathrm{Tl}$ ) and the onset of head rotation (Th) were almost simultaneous. The latencies of both shoulder and pelvis rotation were significantly different from $0(t=5.74$; $\mathrm{p}<0.001$ and $\mathrm{t}=4.08 ; \mathrm{p}<0.01$, respectively), indicating a delay with respect to Tl. Latency of onset of head rotation (Th) was significantly shorter than those of shoulder (Ts; $\mathrm{t}=-3.82 ; \mathrm{p}<0.001$ ) and pelvis rotation (Tp; $\mathrm{t}=3.49$; $\mathrm{p}<0.001$ ), indicating that the onset of head rotation preceded shoulder and pelvis rotation. We found no significant difference, however, between the latencies of shoulder and pelvis rotation. Therefore, controls initiated body rotation
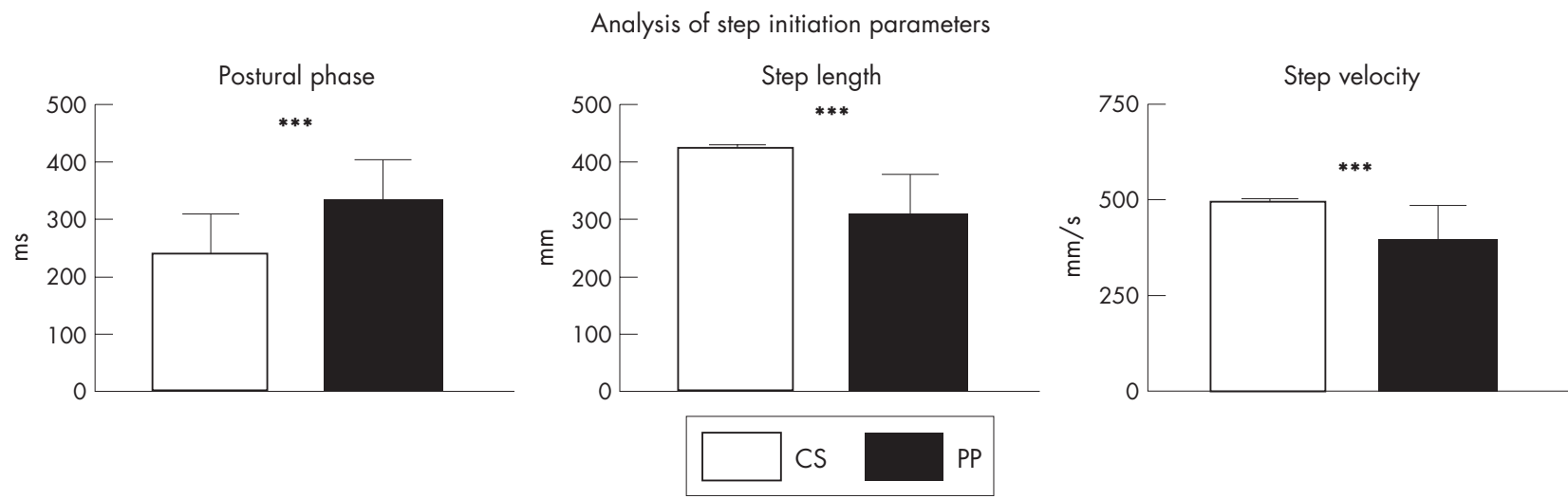

Figure 4 Bar graphs of step initiation variables, comparison between controls (CS, white) and patients with Parkinson's disease (PP, black). Mean (SD) values are given. ${ }^{* *} \mathrm{p}<0.001$. 


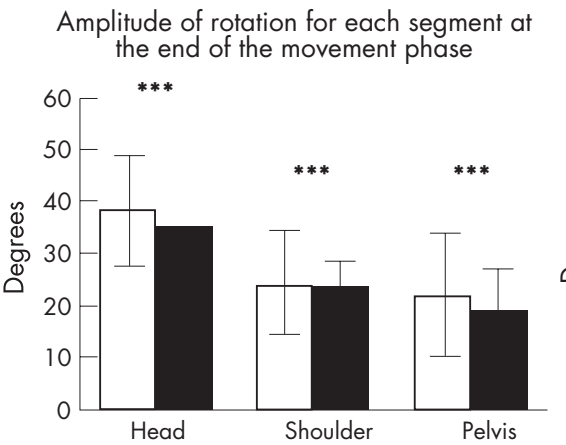

$$
\text { Final amplitude of rotation for each segment }
$$

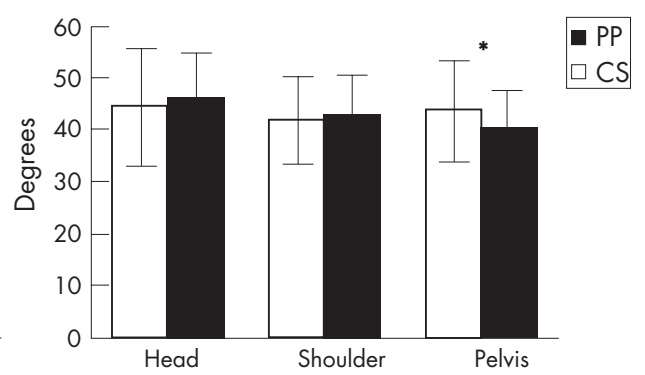

Figure 5 Bar graphs of amplitude of rotation for each segment. Comparison between controls (CS, white) and patients with Parkinson's disease (PP, black). The mean (SD) values are given. ${ }^{*} p<0.05$ and ${ }^{* * *} p<0.001$.

with the head at the beginning of the postural phase and recruited the shoulders coupled with the pelvis.

In patients with Parkinson's disease, the three latencies (head, shoulders and pelvis) were significantly different from $0 \quad(\mathrm{t}=7.35 ; \mathrm{p}<0.001 ; \mathrm{t}=16.24 ; \mathrm{p}<0.001$ and $\mathrm{t}=10.24$; $\mathrm{p}<0.001$, respectively). The latency of head rotation was significantly shorter than those of shoulder (Ts; $t=3.57$; $\mathrm{p}<0.001)$ and pelvis rotation $(\mathrm{Tp} ; \mathrm{t}=4.7 \mathrm{l} ; \mathrm{p}<0.001)$. In contrast with controls, the latency of shoulder rotation was significantly shorter than that of pelvis rotation $(\mathrm{Tp} ; \mathrm{t}=3.18$; $\mathrm{p}<0.01$ ). Obviously, patients with Parkinson's disease started their rotation with the head long after the onset of the postural phase, then continued with the rotation of the shoulders and finally with that of the pelvis. The shoulders were not recruited together with the pelvis but in a top-down sequential organisation.

Influence of step velocity on the sequential onset of shoulder and pelvis rotation

To test the influence of step velocity on the pattern of rotation onset, the coefficient of correlation of the delay between the onset of shoulder and pelvis rotation and step velocity was calculated.

In controls, the coefficient of correlation was not significantly different from $0\left(\mathrm{r}^{2}=0.07\right)$, indicating that there is

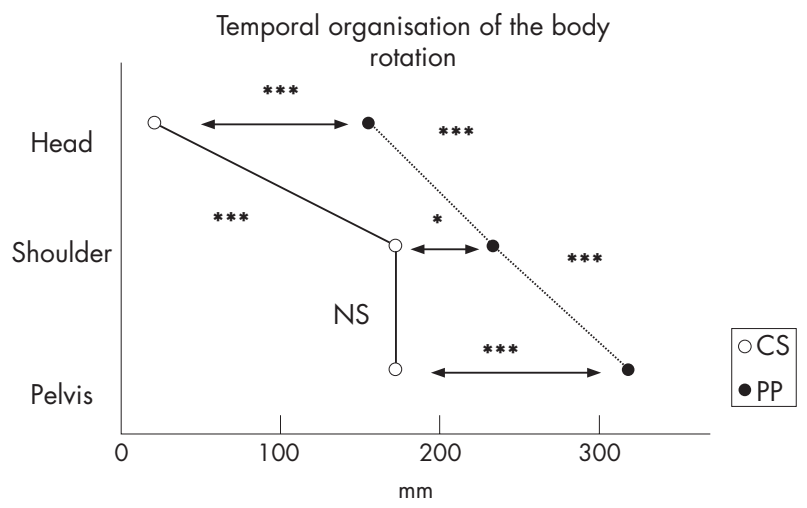

Figure 6 Representation of the temporal organisation of the rotation for patients with Parkinson's disease and controls: comparison between groups and between levels (head, shoulders and pelvis). Horizontal arrows: comparison between groups for a given level. Comparison between levels: on the left and on the right the line joining the onset of segment latencies (left: CS and right: PP). NS, non-significant; ${ }^{*} p<0.05$ and ${ }^{* * *} \mathrm{p}<0.001$. no relationship between the step velocity and the timing of rotation onset. In other words, this indicates that step velocity does not influence the timing of the onset of rotation.

In patients with Parkinson's disease, the same analysis indicates that the latency between shoulders and pelvis rotation does not depend on step velocity $\left(r^{2}=0.1\right)$. Therefore, the uncoupling between onset of shoulder and pelvis rotation is not because of the general slowing of the movement. A set of values with a high delay between shoulder and pelvis, however, is seen only for high-velocity values.

\section{DISCUSSION}

The analysis of body rotation in the population with Parkinson's disease shows a specific impairment of the process of axial rotation. The principal results were (1) a decrease in the gait initiation performance, (2) a coupled shoulder and pelvis rotation and (3) a delayed onset of pelvis rotation with respect to the shoulder, suggesting a specific deficit in coordinating shoulder and pelvis rotation, not due to the slowness in the performance of movement in Parkinson's disease.

\section{Deficits of temporal organisation of body rotation in patients with Parkinson's disease}

As shown in fig 2, in controls, head rotation was the first event accompanying the onset of the postural phase ( $\mathrm{Tl})$, which corresponded to the generation of propulsive forces in the sagittal plane. During the onset of the postural phase, the trunk segment (shoulder and pelvis) started its rotation almost simultaneously. Thus, at the onset of the movement phase (T2), all segments had largely initiated their rotations and the rotation process continued progressively during the execution of the diagonal step. At the end of the movement phase (T3), more than half the trunk rotation had been completed and the rotation of the head segment was almost fully achieved. In patients with Parkinson's disease, the onset of rotation of each segment was clearly delayed in comparison with that of controls. The onset of head rotation intervened only at the middle of the postural phase, whereas that of shoulder rotation intervened at the end of this phase, and that of pelvis rotation intervened even later, with the onset of the movement phase.

Slower movements were not significantly different from faster ones, with a coupled rotation of the shoulder and the pelvis. By contrast, the slowest axial rotations observed in patients with Parkinson's disease were performed in a manner similar to those of controls. In patients, the delay between shoulder and pelvis rotation increased with the 
velocity of rotation, indicating that the delay in pelvis rotation with respect to the shoulder is not due to the slowness of performance of movement in Parkinson's disease but due to an impairment that increases with the velocity of the task.

\section{Mechanisms}

What could be specifically impaired in the capacity of patients with Parkinson's disease to exert simultaneous rotation of the upper and lower trunk? A general deficit may be the reduced reliance on proprioceptive inputs to control the motor output ${ }^{19}$ and the biased functioning of the segmental circuits related to Ia and Ib afferents. ${ }^{20-23}$ The muscles participating in axial rotation are also antigravity muscles, and the impaired functioning of these circuits may be increased compared with that of the flexor muscles. ${ }^{10}$

The main impairment may concern the control of pelvis rotation. The pelvis position in space depends on two control systems. The first is based on a top-down organisation by using the head position in space as a reference frame and calculating the various segment positions in space from the head position. The second is the bottom-up control, which, when a person is standing, regulates the position of the centre of gravity in space as well as to that of the pelvis, where the centre of gravity is located, by using the feetsupport interface as a reference frame. ${ }^{24}{ }^{25}$ The bottom-up control would be mainly related to equilibrium maintenance and would be more severely impaired in patients with Parkinson's disease, owing to the reduced capacity to generate ground reaction forces, ${ }^{14-17}$ in connection with a biased assessment of the effort exerted by the extensor muscles against gravity. ${ }^{26}$ By contrast, the control of head and trunk rotation, which depends on the descending chain, would be less impaired in those with Parkinson's disease, and the onset of shoulder rotation would occur earlier than that of pelvis rotation.

An impairment of coordination between the top-down and bottom-up control can also be put forward to explain the parkinsonian impairment in whole-body rotation. In Parkinson's disease, the difficulty of performing two motor tasks simultaneously has been described for a long time: ${ }^{27}$ this phenomenon is well known in clinical practice, with the classic description of a patient being unable to walk and simultaneously to put his wallet into his inside pocket. ${ }^{28}$ This underlines the role of the basal ganglia and supplementary motor area output in providing the person with an internal timing cue for movement and postural sequences. ${ }^{29} 30$

\section{Study limitations}

These data on a small group of selected patients with advanced Parkinson's disease (Hoehn-Yahr stages III and IV), however, are clearly not applicable to patients at earlier stages of disability without any axial motor impairment during daily living.

\section{Conclusions}

The specific impairment of temporal organisation of the axial rotation in patients with Parkinson's disease may reflect two aspects. The first would be related to a general role of the basal ganglia in body orientation in space. The delayed onset of the head rotation in patients with Parkinson's disease as compared with that in controls may be related to the impaired orientation in patients with Parkinson's disease. The second aspect would be a major deficit in coordinating the descending control of body segment orientation starting from the head and acting on the shoulder with the ascending control of the pelvis orientation in space starting from the feet. The difficulty in Parkinson's disease to produce ground reaction forces responsible for positioning of the centre of gravity in space would explain the uncoupling between shoulder and pelvis rotation and the delayed onset of pelvis rotation. This impaired generation of ground reaction forces may be due to a deficit relating to the extensors Ib input, monitoring the muscle effort against gravity.

\section{ACKNOWLEDGEMENTS}

We thank Dr B Amblard for critically reviewing the manuscript and Dr M Suzan Macalister for revising the English. This investigation was supported by a grant from the French Ministry of Health (Programme Hospitalier de Recherche Clinique 1995).

\section{Authors' affiliations}

M Vaugoyeau, C Assaiante, S Mesure, Groupe Développement et Pathologie de l'Action, CNRS UMR 6196, Marseille, France F Viallet, R Aurenty, Centre Hospitalier du pays d'Aix Service de Neurologie, Aix en Provence, France

F Viallet, J Massion, CNRS UMR 6057, Aix en Provence

Competing interests: None declared.

\section{REFERENCES}

1 Lakke JP, van Weerden TW, Staal-Schreinemachers A. Axial apraxia, a distinct phenomenon. Clin Neurol Neurosurg 1984;86:291-4.

2 Lakke JP. Axial apraxia in Parkinson's disease. J Neurol Sci 1985;69:37-46.

3 Schenkman ML, Clark K, Xie T, et al. Spinal movement and performance of a standing reach task in participants with and without Parkinson disease. Phys Ther 2001:81:1400-11.

4 Steiger MJ, Thompson PD, Marsden CD. Disordered axial movement in Parkinson's disease. J Neurol Neurosurg Psychiatry 1996;61:645-8.

5 Fahn S, and members of the UPDRS Development Committee. In: Fahn S, Marsden CD, Goldstein M, Calne DB, eds. Recent development in Parkinson's disease, Vol II. New York: Mc Millan, 1987:153-63.

6 Schieppati $M$, Hugon $M$, Grasso $M$, et al. The limits of equilibrium in young and elderly normal subjects and in parkinsonians. Electroencephalogr Clin Neurophysiol 1994:93:286-98.

7 Dietz V. Human neuronal control of automatic functional movements: interaction between central programs and afferent input. Physiol Rev 1992; 72:33-69.

8 Dietz V. Reflex behavior and programming in Parkinson's disease. Adv Neurol 1993;60:375-80.

9 Dietz V, Berger W, Horstmann GA. Posture in Parkinson's disease: impairment of reflexes and programming. Ann Neurol 1988;24:660-9.

10 Dietz V, Gollhofer A, Kleiber M, et al. Regulation of bipedal stance: dependency on "load" receptors. Exp Brain Res 1992;89:229-31.

11 Dietz V, Colombo G. Influence of body load on the gait pattern in Parkinson's disease. Mov Disord 1998;13:255-61.

12 Azulay JP, Mesure S, Amblard B, et al. Visual control of locomotion in Parkinson's disease. Brain 1999;122:111-20.

13 Forssberg $H$, Johnels B, Steg $G$. Is parkinsonian gait caused by a regression to an immature walking pattern? Adv Neurol 1984;40:375-9.

14 Crenna P, Frigo C, Giovannini P, et al. The initiation of gait in Parkinson's disease. In: Marsden CD, ed. Motor disturbances. Vol II. New York: Academic Press, 1990: 161-73.

15 Dietz V, Leenders KL, Colombo G. Leg muscle activation during gait in Parkinson's disease: influence of body unloading. Electroencephalogr Clin Neurophysiol 1997;105:400-5.

16 Gantchev N, Viallet F, Aurenty R, et al. Impairment of posturo-kinetic coordination during initiation of forward oriented stepping movements in parkinsonian patients. Electroencephalogr Clin Neurophysiol 1996;101:110-20.

17 Vaugoyeau M, Viallet F, Mesure S, et al. Coordination of axial rotation and step execution: deficits in Parkinson's disease. Gait Posture 2003;18:150-7.

18 Ferrigno G, Pedotti A. ELITE: a digital dedicated hardware system for movement analysis via real-time TV signal processing. IEEE Trans Biomed Eng 1985;32:943-50.

19 Rickards C, Cody FW. Proprioceptive control of wrist movements in Parkinson's disease. Reduced muscle vibration-induced errors. Brain 1997:120(Pt 6):977-90.

20 Ohye C, Tsukahara N, Narabayashi H. Rigidity and disturbance of reciprocal innervation. Confin Neurol 1965;26:24-40.

21 Hayashi A, Kagamihara Y, Nakajima Y, et al. Disorder in reciprocal innervation upon initiation of voluntary movement in patients with Parkinson's disease. Exp Brain Res 1988;70:437-40.

22 Delwaide PJ, Pepin JL, Maertens de Noordhout A. Contribution of reticular nuclei to the pathophysiology of parkinsonian rigidity. Adv Neurol 1993;60:381-5.

23 Meunier S, Pol S, Houeto JL, et al. Abnormal reciprocal inhibition between antagonist muscles in Parkinson's disease. Brain 2000;123:1017-26.

24 Mergner T, Rosemeier T. Interaction of vestibular, somatosensory and visual signals for postural control and motion perception under terrestrial and microgravity conditions-a conceptual model. Brain Res Rev 1998;28:118-35. 
25 Assaiante C, Amblard B. An ontogenetic model of sensorimotor organization of balance control in humans. Hum Mov Sci 1995;14:13-43.

26 Dietz V, Horstmann GA, Tripel $M$, et al. Human postural reflexes and gravity-an under water simulation. Neurosci Lett 1989;106:350-5.

27 Georgiou N, lansesek R, Bradshaw JL, et al. An evaluation of the role of internal cues in the pathogenesis of parkinsonian hypokinesia. Brain 1993; 116:1575-87
28 Schwab RS Chafetz ME Walker S Control of two simultaneous voluntary motor acts in normals and parkinsonism. Arch Neurol Psychiatry 1954;150:345-57. 29 Marsden CD. The mysterious motor function of the basal ganglia: the Robert Wartenberg lecture. Neurology 1982;32:514-39.

30 Cunnington R, lansek R, BradshawJL, et al. Movement-related potentials in Parkinson's disease. Presence and predictability of temporal and spatial cues. Brain 1995; 118:935-50.

\section{Clinical Evidence-Call for contributors}

Clinical Evidence is a regularly updated evidence-based journal available worldwide both as a paper version and on the internet. Clinical Evidence needs to recruit a number of new contributors. Contributors are healthcare professionals or epidemiologists with experience in evidence-based medicine and the ability to write in a concise and structured way.

Areas for which we are currently seeking contributors:

- Pregnancy and childbirth

- Endocrine disorders

- Palliative care

- Tropical diseases

We are also looking for contributors for existing topics. For full details on what these topics are please visit www.clinicalevidence.com/ceweb/contribute/index.jsp

However, we are always looking for others, so do not let this list discourage you.

Being a contributor involves:

- Selecting from a validated, screened search (performed by in-house Information Specialists) epidemiologically sound studies for inclusion.

- Documenting your decisions about which studies to include on an inclusion and exclusion form, which we keep on file.

- Writing the text to a highly structured template (about 1500-3000 words), using evidence from the final studies chosen, within 8-10 weeks of receiving the literature search.

- Working with Clinical Evidence editors to ensure that the final text meets epidemiological and style standards.

- Updating the text every 12 months using any new, sound evidence that becomes available. The Clinical Evidence in-house team will conduct the searches for contributors; your task is simply to filter out high quality studies and incorporate them in the existing text.

If you would like to become a contributor for Clinical Evidence or require more information about what this involves please send your contact details and a copy of your CV, clearly stating the clinical area you are interested in, to CECommissioning@bmigroup.com.

\section{Call for peer reviewers}

Clinical Evidence also needs to recruit a number of new peer reviewers specifically with an interest in the clinical areas stated above, and also others related to general practice. Peer reviewers are healthcare professionals or epidemiologists with experience in evidence-based medicine. As a peer reviewer you would be asked for your views on the clinical relevance, validity, and accessibility of specific topics within the journal, and their usefulness to the intended audience (international generalists and healthcare professionals, possibly with limited statistical knowledge). Topics are usually 1500-3000 words in length and we would ask you to review between 2-5 topics per year. The peer review process takes place throughout the year, and out turnaround time for each review is ideally 10-14 days.

If you are interested in becoming a peer reviewer for Clinical Evidence, please complete the peer review questionnaire at www. clinicalevidence.com/ceweb/contribute/peerreviewer.jsp 